\title{
Transcervical Foley's catheter: a promising option for induction of labour
}

Sir,

We hereby report the results of a small randomized prospective study where we compared the efficiency and efficacy of transcervical extra-amniotic Foley catheter placement to intravaginal dinoprostone gel as a method of induction of labour.

Antenatal women admitted to the labour room for labour induction after meeting inclusion criteria of the study were asked to participate. After informed consent 25 received vaginal Dinoprostone gel while in 25 labour induction was done with transcervical extra-amniotic Foley's catheter for cervical ripening. Inclusion criteria included singleton term pregnancy with cephalic presentation with intact membranes and Biophysical Score of $8 / 8$. Exclusion criteria was; pre-induction Bishop's Score of $>6$, cervical dilatation $>2 \mathrm{~cm}$, evidence of cephalo-pelvic disproportion, antepartum hemorrhage, comorbid medical conditions, previous scar and contraindication to prostaglandins. Labour was monitored and partogram was maintained. The women were randomly assigned to two groups. In women of group assigned for Foley's induction, 16 Fr Foley's catheter was inserted transcervically under direct vision during per speculum examination. Once placed, balloon was inflated with $50 \mathrm{ml}$ of normal saline and Foley's was fixed to the medial aspect of thigh with traction till expulsion or earlier in case of Rupture Of Membranes (ROM). If not expelled catheter balloon was deflated and removed after 24 hours and reassessed. For dinoprostone group, $0.5 \mathrm{mg}$ in $3 \mathrm{gm}$ base of dinoprostone was administered intravaginally every 6 hours for maximum of 3 doses. The women who failed to go in labour or had ROM or where a labour abnormality was diagnosed received oxytocin beginning with $2 \mathrm{mIU} / \mathrm{min}$ increased by $2 \mathrm{mIU} / \mathrm{min}$ and titrated till effective uterine contractions were achieved or maximum of $32 \mathrm{mIU} / \mathrm{min}$. Induction-Delivery interval, mode of delivery and neonatal outcome was noted. Women in both the groups were similar in terms of age parity, gestational age at delivery, pre-induction Bishop's Score. The induction delivery interval was significantly shorter in the Foley's catheter group (18.3 \pm 4.8 hours) as compared to dinoprostone group (24.4 \pm 4.5 hours).
Significantly less number of women in the Foley's group required additional oxytocin as compared to the dinoprostone group. APGAR score of the neonate and rates of neonatal resuscitation and NICU admission were similar in both groups. Vaginal delivery was achieved in $100 \%$ of cases in both groups.

The comparison of the two modalities of which one is mechanical with no medical side effects had been done earlier butwith different protocols. ${ }^{1-3}$ With mechanical dilatation by Foley's catheter we achieved reduction in Induction-Delivery interval in about $25 \%$ cases compared to the intravaginal prostaglandin. Studies with bigger sample size can be conducted to establish the Foley's as a promising side-effects free, non-medical \& cost-effective option for labour induction. Patients with previous LSCS can also be enrolled in the study where prostaglandins are sparingly used as induction agent. This data can provide platform for designing a large scale study.

Divya Pandey*, Sudha Salhan Department of Obstetrics and Gynaecology, North Delhi Municipal Corporation Medical College and Hindu Rao Hospital, Delhi-7, India

*Correspondence to: Dr. Divya Pandey, E-mail: dr_devya1@yahoo.co.in

\section{REFERENCES}

1. Dahiya K, Malik K, Dahiya A, Nanda S. Comparison of the efficacy of Foley catheter balloon with dinoprostone gel for cervical ripening at term. Int $\mathbf{J}$ Clin Med. 2012;3:527-31.

2. Barrilleaux PS, Bofill JA, Terrone DA, Magann EF, May WL, Morrison JC. Cervical ripening and induction of labor with misoprostol, dinoprostone gel and a Foley catheter: a randomized trial of 3 techniques. Am J Obstet Gynecol. 2002;83(2):211-3.

3. Vaknin Z, Kurzweil Y, Sherman D. Foley catheter balloon vs. locally applied prostaglandins for cervical ripening and labor induction: a systematic review and metaanalysis. Am J Obstet Gynecol. 2010;203(5):418-29.

DOI: 10.18203/2320-1770.ijrcog20150134

Cite this article as: Pandey D, Salhan S. Transcervical Foley's catheter: a promising option for induction of labour. Int J Reprod Contracept Obstet Gynecol 2015;4:933. 